Research Article

\title{
The Environmental Effects Induced by a Metro Shield Tunnel Side-Crossing on Adjacent Pile Foundations and Its Impact Partition
}

\author{
Hui Hu, ${ }^{1}$ Yimo Zhu, ${ }^{1}$ Gang Zhang, ${ }^{1}$ Heng Zhang ${ }^{\mathbb{D}},{ }^{1}$ and Peng Tu$^{2}$ \\ ${ }^{1}$ Key Laboratory of Transportation Tunnel Engineering, Ministry of Education, Southwest Jiaotong University, \\ Beijing 610031, China \\ ${ }^{2}$ Sichuan Vocational and Technical College of Communications, Chengdu 611130, China \\ Correspondence should be addressed to Heng Zhang; tunnelzh@home.swjtu.edu.cn
}

Received 25 September 2019; Revised 31 October 2020; Accepted 19 December 2020; Published 4 January 2021

Academic Editor: Jian Ji

Copyright (C) 2021 Hui Hu et al. This is an open access article distributed under the Creative Commons Attribution License, which permits unrestricted use, distribution, and reproduction in any medium, provided the original work is properly cited.

\begin{abstract}
With the advantages of fast construction speed and small disturbance to stratum, shield tunneling is becoming the preferred construction scheme for metro construction. However, if the disturbance of stratum cannot be clearly understood, it will affect the safety of adjacent underground structures and aboveground buildings. Based on the construction of the interval tunnel between Shizishan station and Chuanshi station of Chengdu metro line 7 project, this paper proposed a simplified calculation method to analyze the impact of shield excavation on adjacent pile foundation. A two-stage method of modified Peck formula and Winkler elastic foundation model was used to investigate the additional displacement and internal force of pile. A three-dimensional numerical model validated with the field test data was performed to compare with the theoretical results. The impact factors and their impact degree were discussed. The results show that the additional displacement and internal force are at a reasonable and acceptable level. The permanent pile foundation should adopt the small diameter pile as far as possible. When the small diameter pile foundation cannot meet the stress requirements, the design scheme of the pile group should be adopted. The area around shield tunnel is divided into strong impact area of pile foundation $(S \leq 0.75 \mathrm{D})$, slight impact area $(0.75 \mathrm{D} \leq S \leq 1.5 \mathrm{D})$, and no impact area $(S>1.5 \mathrm{D})$. The pile researched in this paper $(S=0.83 \mathrm{D})$ is in the slight impact area.
\end{abstract}

\section{Introduction}

With the continuous progress of urbanization in China, the urban population is growing, and urban traffic pressure is also increasing. Metro has the advantages of large passenger capacity, fast speed, and full use of underground space, which is more and more popular in the modern society. However, the urban subway has strict requirements for its construction methods. Because of the high density of buildings in cities, the construction of the metro will cause stratum movement and bring adverse effects on ground buildings. Especially when passing through high-rise buildings, the disturbance caused by construction on stratum must be more strictly controlled. The construction period of metro is long, and the interruption of traffic should be avoided as far as possible when crossing the road. With the advantages of fast construction speed and small disturbance to stratum, shield tunneling is becoming the preferred construction scheme for metro construction [1-6].

Although shield tunneling has many advantages as mentioned above, and the construction technology has made great progress after many years of development, due to the defects of geological conditions and construction technology, the advance of shield tunneling will inevitably make a disturbance on the stratum, change the stress state of soil, and cause additional internal force and deformation of adjacent buildings and pipelines. If the disturbance of stratum cannot be clearly understood, it will affect the safety of adjacent underground structures and aboveground buildings. Among these potential safety hazards, the problem of shield tunneling closely passing through bridges or building piles is one of the most frequently encountered 
problems. Therefore, how to analyze the impact of tunnel construction on the adjacent pile foundation fast and accurately has always been a hot issue in the design and construction of urban metro [7-9].

Over the years, previous researchers have done numerous studies on methods to evaluate the effects of shield tunnel construction on the existing pile foundations and achieved some results [10-15]. These analysis methods can be divided into two categories: one is complete numerical simulation analysis, including simultaneous simulation of pile, soil, and tunnel excavation. The other is a simplified two-stage method, which involves the initial separation of soil and pile, so that the soil motion can be calculated first and then imposed to the pile. Complete numerical simulation analysis is usually based on a three-dimensional finite element model (FEM) or finite difference model (FDM) analysis, which provides a complete solution for tunnel-soilpile interaction [16-21]. However, considering the nonlinear soil behavior and complex construction sequence, such analysis will become more uncertain due to the errors in the construction of three-dimensional model, the high sensitivity to the grid meshing, the distribution of mechanical properties of elements at the pile-soil interface, the interaction with adjacent structures, and the modeling of excavation sequence. Simulated costs can also become very high.

Because of the simplicity and accuracy of the calculation process, the two-stage analysis method can be used to make up for the shortcomings of the above-mentioned complete numerical simulation analysis, so it has been widely used and developed [22-25]. Basile researched the effects induced by tunneling on existing pile foundations through a two-stage procedure and a computer program PGROUPN for pilegroup analysis based on a nonlinear boundary element solution [26]. Zhang et al. proposed a simplified solution based on Pasternak's foundation model to predict the lateral displacements and internal forces of a single-pile and grouppiles induced by tunneling considering the effects of lateral soil displacements [27]. Wu et al. proposed a soil-tunnel interaction model based on the Timoshenko beam simplified model (TBSM) of the tunnel [28]. Franza et al. presented an elastic study of tunnel-pile-structure interaction through Winkler-based Two-Stage Analysis Methods (TSAMs), focusing on structural displacements resulting from tunnel excavation beneath piled frames or simple equivalent beams [29]. However, in the existing research, most of their solutions are complex, the mechanical state of pile foundation and its impact factors are not analyzed enough, and the connection with engineering project is not close enough, which is not conducive to practical application, so further improvement is needed.

Based on the two-stage method of modified Peck formula and Winkler elastic foundation model, this paper studied the impact of shield tunnel construction on adjacent pile foundation and analyzed the mechanical state of pile foundation and its impact factors by theoretical derivation and numerical simulation. And according to the variation degree of additional internal force of pile foundation, the stratum around the tunnel is divided into a strong impact zone, weak impact zone, and no impact zone, which can provide guidance and reference for the design and construction of similar underground projects in the future.

\section{Project Overview}

Chengdu Metro Line 7 is an important rail transit line in Chengdu, China. It links up Chengdu Railway Station, Chengdu East Railway Station, and Chengdu South Railway Station and forms transfer relations with several urban rapid rail transit and regional rail transit radiation lines. Chengdu Metro Line 7 is a loop line, circling the city outside the Second Ring Road with a total length of $38.61 \mathrm{~km}$, and the whole journey is underground. The project in this paper is an interval tunnel between Shizishan Station and Chuanshi Station. The tunnel consists of two single-track tunnels with a total length of $970.4 \mathrm{~m}$, in a northeast-southwest direction. The location of the interval tunnel is shown in Figure 1.

The stratum that the tunnel passes through is mainly the Quaternary bottom cover, and the surface is mostly a small amount of artificial filling of the Quaternary miscellaneous fill. The lower part is the Quaternary lower Pleistocene glacial water deposit, the clay of impact origin, and the lower part is the weathered mudstone of the Cretaceous upper Guankou Formation. The tunnel is located on the thirdgrade terrace of Minjiang River in the western Sichuan plain. It is a Piedmont landform with surface water being gully water. Groundwater is not extremely abundant, and the groundwater level is below $15 \mathrm{~m}$.

The location of the tunnel is extremely complex and sensitive. Around the tunnel are Wanke City Garden, Sichuan Normal University Hospital, Jiahe Garden, and other buildings. Furthermore, rainwater and gas pipelines are also densely distributed in this area. But one of the most serious problems is the left line tunnel closely passing through the East No. 1 Pile of Wanke City Garden Building 59. The distance between the pile foundation and the center of the left line of the tunnel is only $5 \mathrm{~m}$. Therefore, how to evaluate the interaction between shield, soil, and existing building pile foundation in the construction process is extremely important to limit the risk of damage to existing buildings.

\section{Basic Theory and Calculation Method}

Based on the two-stage method of modified Peck formula and Winkler elastic foundation model, the analysis is carried out in this part. The horizontal displacement coordinate system of stratum is $U_{(z)}-O-Z$ and that of pile foundation is $W_{(z)}-O-Z$. The two coordinate systems coincide as shown in Figure 2.

The first stage is the deformation of stratum around the pile caused by tunnel excavation, and in this stage, the impact of the pile on stratum deformation is not considered at this time. The original Peck formula is derived in clay conditions, then it is improved to use in other kinds of rock and soil mass [30-33]. Han, through statistical analysis and practical investigation, found that Peck formula can be well applied in China [34]. The modified Peck empirical formula can solve the stratum settlement $S_{(x, z)}$ at any depth and the free horizontal displacement $U_{(x, z)}$ of stratum at pile 


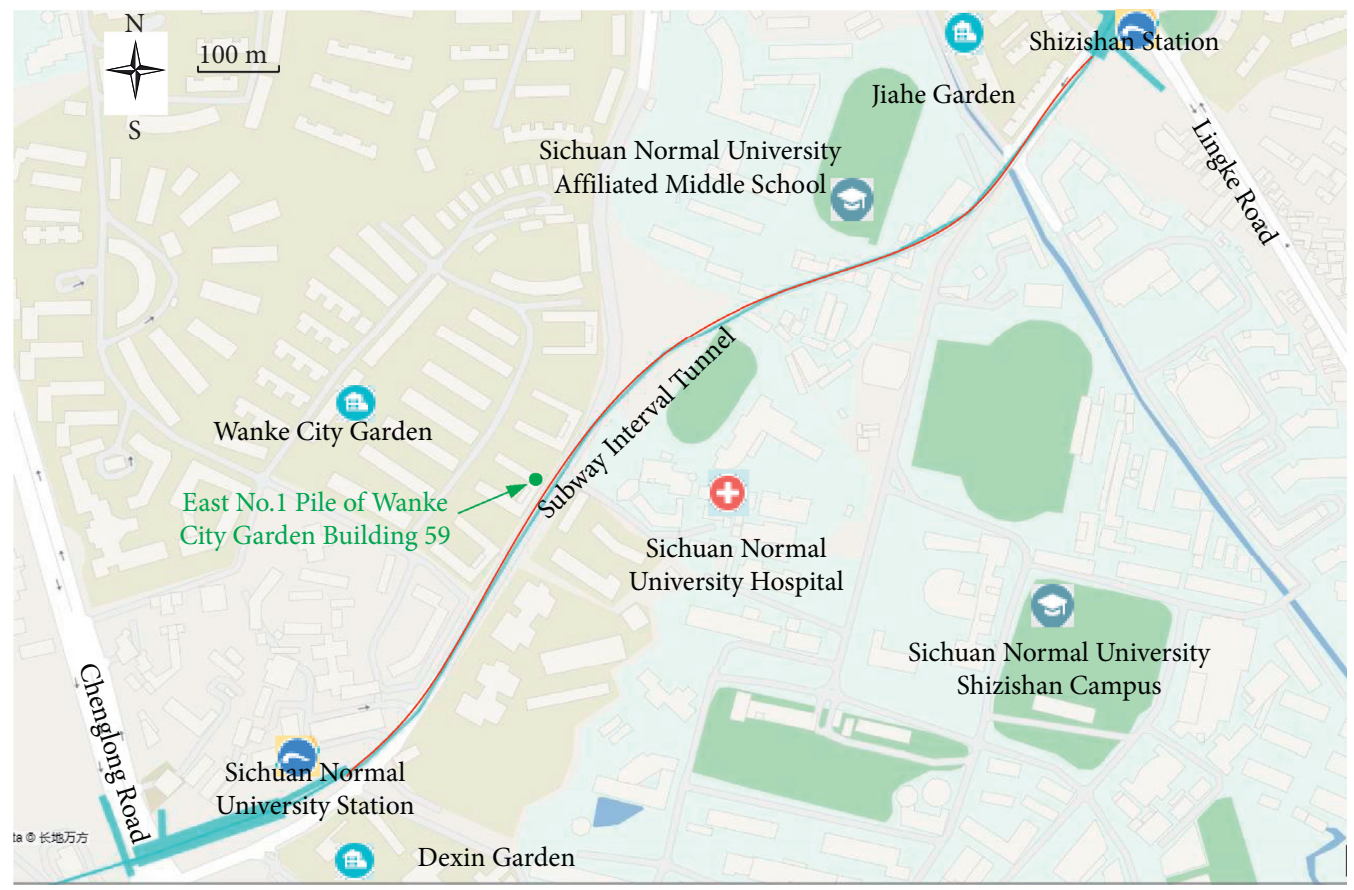

FIgURE 1: The location of the interval tunnel.

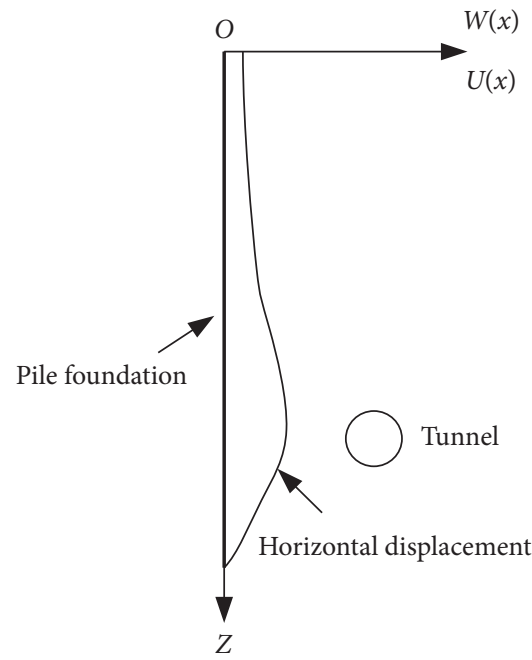

FIGURE 2: The coordinate system of horizontal displacement.

foundation caused by shield tunneling, and the $U_{(x, z)}$ is fitted into a polynomial $U_{(z)}$ for the convenience of the second stage solution $[35,36]$. The diagram of Peck formula is shown in Figure 3.

$$
\begin{aligned}
S(x, z) & =\frac{V_{S}}{\sqrt{2 \pi i_{Z}}} \exp \left(-\frac{x^{2}}{2 i_{Z}^{2}}\right), \\
U(x, z) & =\frac{-a K V_{S} x}{\sqrt{2 \pi i_{Z}^{2}}} \exp \left(-\frac{x^{2}}{2 i_{Z}^{2}}\right), \\
i_{Z} & =(H-a z) K,
\end{aligned}
$$

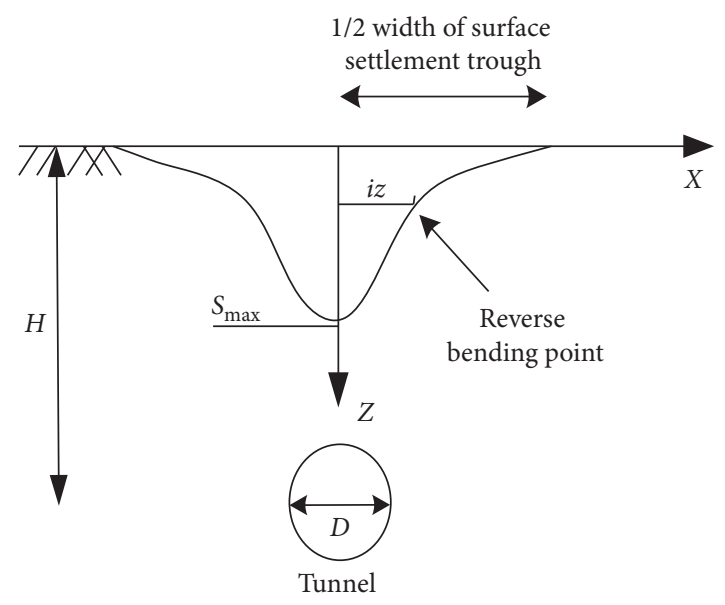

FIgure 3: The diagram of Peck formula.

where $x$ is the horizontal distance from the central axis of the tunnel $(\mathrm{m}) ; z$ is the vertical distance from the ground surface $(\mathrm{m}) ; i_{z}$ is the horizontal distance between the reverse bending point of settlement curve and the central axis of tunnel (m); $V_{S}$ is the ground loss per unit length caused by tunnel excavation $\left(\mathrm{m}^{3} / \mathrm{m}\right) ; H$ is the burial depth of tunnel center; $K, a$ are statistical parameters, generally for cohesive soil layer, $K=0.4 \sim 0.7, a=0.65$, for sandy soil layer $K=0.2 \sim 0.3, a=0.5$.

In the second stage, the pile is regarded as an elastic foundation beam. The interaction between pile and stratum is simulated by Winkler foundation spring with a single parameter. The stratum displacement obtained in the first stage is applied to the structure, and the equilibrium differential equation is established. The additional displacement and internal force of pile foundation are analyzed by 
solving the differential equation. The soil is idealized as a linear elastic body. It is assumed that the stress at any point on the side of the pile foundation is proportional to the horizontal displacement of the soil at that point, but not related to the stress and settlement at other points in the soil. That is to say, the soil is composed of a series of spring elements that are close to each other and independent of each other, and the soil is not subject to shear stress.

3.1. The Fundamental Assumption. The initial horizontal load on the pile is triangular distribution:

$$
\sigma(z)=\gamma \times z .
$$

The interaction between pile foundation and stratum is simulated by Winkler foundation spring, and there is no separation between pile foundation and stratum [37-40]. When the tunnel has not been constructed and ground displacement has not occurred, the deformation of foundation spring is

$$
\varepsilon_{0}(z)=\frac{\sigma(z)}{k_{h}} .
$$

The reaction force of foundation spring is proportional to its deformation,

$$
q(z)=\left(W(z)+\varepsilon_{0}(z)-U(z)\right) \times k_{h},
$$

where $\gamma$ is the density of soil; $z$ is the burial depth; $k_{h}$ is the product of horizontal soil bed coefficient $k_{h}^{\prime}$ and pile diameter $D$.

3.2. The Equilibrium Differential Equation. The whole pile is divided into many microelements, and the additional stress mode of each microelement is shown in Figure 4. Based on the static equilibrium condition of microelement, it can be concluded that

$$
-\mathrm{Q}+(\mathrm{Q}+\mathrm{d} \mathrm{Q})-q \mathrm{~d} z+\sigma \mathrm{d} z=0 .
$$
that

After arrangement and replacement, it can be obtained

$$
\frac{\mathrm{dQ}}{\mathrm{d} z}=(w-u) \times k_{h},
$$

and

$$
\left\{\begin{array}{l}
\frac{\mathrm{d} Q}{\mathrm{~d} z}=\frac{\mathrm{d}^{2} M}{\mathrm{~d} z^{2}}, \\
E I \frac{\mathrm{d}^{4} w}{\mathrm{~d} z 4}=-\frac{\mathrm{d}^{2} M}{\mathrm{~d} z^{2}} .
\end{array}\right.
$$

So, equation (6) can be transformed as

$$
E I \frac{\mathrm{d}^{4} w}{\mathrm{~d} z^{4}}=(u-w) \times k_{h} .
$$

That is, the equilibrium differential equation

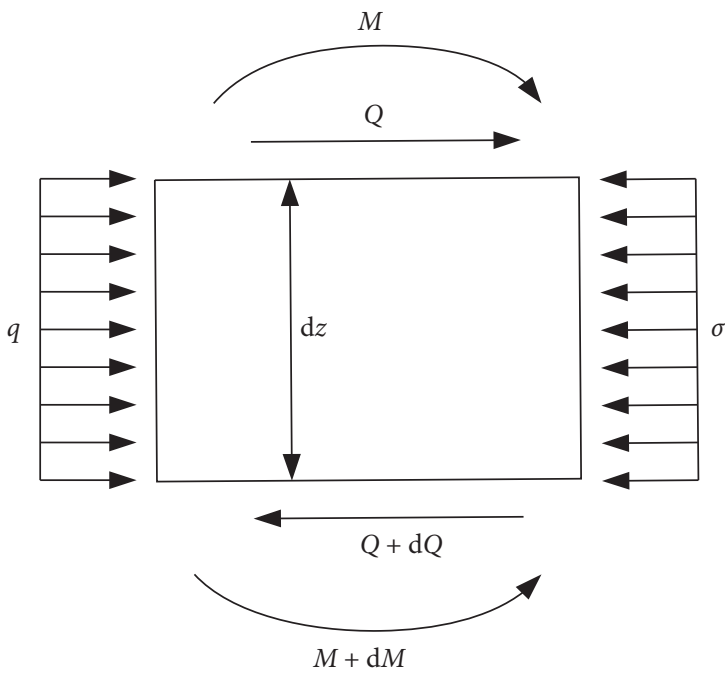

Figure 4: The microelement of pile.

$$
E I \frac{\mathrm{d}^{4} w}{\mathrm{~d} z 4}+w k_{h}=u k_{h},
$$

where $E$ is the elastic modulus of pile; $I$ is the inertial moment of pile, $I=\left(\pi D^{4} / 64\right) ; D$ is the pile diameter.

3.3. Boundary Conditions. The bottom of the pile is regarded as a free boundary. There is no concentrated horizontal load; the shear force of the pile bottom surface is zero. There is no bending moment load; the bending moment of the pile bottom surface is zero. That is, when $z=H$,

$$
\begin{aligned}
& E I \frac{\mathrm{d}^{3} w}{\mathrm{~d} z^{3}}=0, \\
& E I \frac{\mathrm{d}^{2} w}{\mathrm{~d} z^{2}}=0 .
\end{aligned}
$$

Although the top of pile is constrained by building foundation, if the building is based on a small independent foundation, which is deformed together with the ground, therefore, the constraints are small and can also be regarded as a free boundary. That is, when $z=0$,

$$
\begin{aligned}
& E I \frac{\mathrm{d}^{3} w}{\mathrm{~d} z^{3}}=0, \\
& E I \frac{\mathrm{d}^{2} w}{\mathrm{~d} z^{2}}=0 .
\end{aligned}
$$

3.4. Solutions. The homogeneous differential equation of equation (9) is

$$
E I \frac{\mathrm{d}^{4} w}{\mathrm{~d} z^{4}}+w k_{h}=0
$$

Its general solution is 


$$
w^{0}=e^{\lambda y}\left(c_{1} \cos \lambda y+c_{2} \sin \lambda y\right)+e^{-\lambda y}\left(c_{3} \cos \lambda y+c_{4} \sin \lambda y\right)
$$

where $\lambda=\sqrt[4]{k_{h} / 4 E I}$, and $c_{1}, c_{2}, c_{3}, c_{4}$ are undetermined constants, which can be determined by boundary conditions,

$$
\left\{\begin{array}{l}
w_{z=0, H}^{0}(2)+w_{z=0, H}^{*}(2)=0 \\
w_{z=0, H}^{0}(3)+w_{z=0, H}^{*}(3)=0
\end{array}\right.
$$

Bring the fitting polynomial $w^{*}=U(z)$ of the first stage into equation (14), and the final displacement solution of pile foundation can be obtained:

$$
w=e^{\lambda y}\left(c_{1} \cos \lambda y+c_{2} \sin \lambda y\right)+e^{-\lambda y}\left(c_{3} \cos \lambda y+c_{4} \sin \lambda y\right)+\sum_{i=0}^{n} a_{i} z^{i} .
$$

Furthermore, the additional bending moment and the additional shear force can be obtained from equation (15):

$$
\begin{aligned}
& M=-E I \frac{\mathrm{d}^{2} w}{\mathrm{~d} z^{2}}, \\
& Q=-E I \frac{\mathrm{d}^{3} w}{\mathrm{~d} z^{3}} .
\end{aligned}
$$

\section{Application of Engineering Project}

Based on the typical engineering project of the left line tunnel closely passing through the East No. 1 Pile of Wanke City Garden Building 59 in the interval tunnel between Shizishan station and Chuanshi station of Chengdu metro line 7 , the distance between the pile and the tunnel is $5 \mathrm{~m}$. The length and diameter of pile are $20 \mathrm{~m}$ and $0.3 \mathrm{~m}$, respectively. The Earth pressure balance shield is adopted with a burial depth of $15 \mathrm{~m}$, and its external diameter is $6.28 \mathrm{~m}$. Because the external diameter of segment is $6 \mathrm{~m}$, there is a gap at the shield tail, which needs to be grouting-filled. The position relation of pile and tunnel is shown in Figure 5.

4.1. Parameters Validation. In order to ensure the adaptability of statistical parameters and models, focusing on the ground settlement, a three-dimension numerical model is built, as Figure 6 shows, to compare theory calculation. In this numerical calculation, finite difference software Flac ${ }^{3 \mathrm{D}}$ is adopted. The soil is simulated by Mohr Coulomb model and solid element. The pile and segment are simulated by pile element and shell element, respectively. The height of the model is $40 \mathrm{~m}$, which is consistent with the thickness of the actual bearing soil layer. Avoiding the effect of boundary effect, the horizontal and longitudinal directions of the model are $120 \mathrm{~m}$ and $100 \mathrm{~m}$, respectively. The physical and mechanical parameters of soil are mainly obtained by laboratory tests and point load tests. By using the standard soil test method [41], the test results are shown in Table 1.

The ground settlement obtained by numerical simulation and theory calculation is fitted in Figure 7. Most parts of

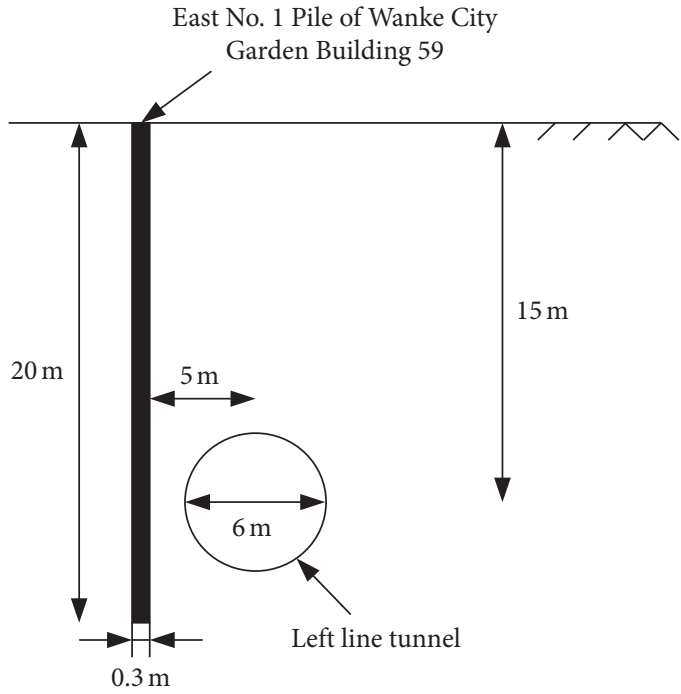

Figure 5: The position relation of pile and tunnel.

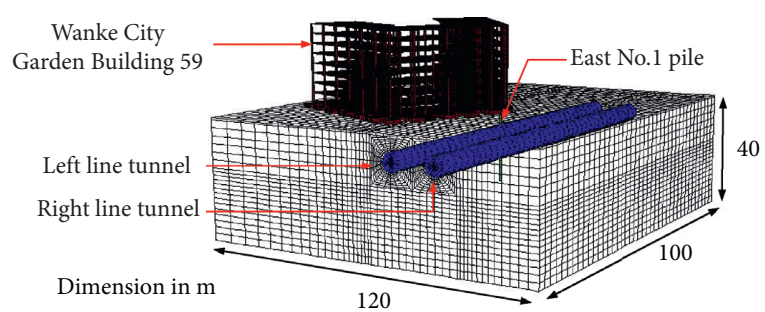

Figure 6: Three-dimension numerical model.

the two curves are in good agreement, and until the horizontal distance from the central axis of the tunnel reaches $14 \mathrm{~m}$, there is a slight deviation between the two. And more importantly, after the field monitoring data is written in, the difference among them is obvious, but acceptable. With the decrease of the horizontal distance from the central axis of the tunnel, the difference tends to increase and reaches a maximum at the center of the settlement trough. The maximum of ground settlement $S_{\max }$ calculated by modified Peck formula is $-8.6 \mathrm{~mm}, S_{\max }$ for field monitoring is $-9.7 \mathrm{~mm}$, the difference is $1.1 \mathrm{~mm}$, and the deviation rate is $12.79 \%$. This shows that the settlement troughs obtained by numerical simulation and theoretical calculation are acceptable, and the selected parameters and models are reasonable. If the difference is too large, parameters can be modified through a back-analysis method based on the field monitoring data.

4.2. Calculation Result of Pile. After parameters validation, the two-stage calculations of pile are carried out based on the process introduced in Section 3. The horizontal displacement of pile is shown in Figure 8. The results of the two-stage method and numerical simulation presented are generally close, but there are relatively large differences at the bottom of the pile and at the peak displacement. Specifically, the maximum displacement of the two-stage method is larger, and the bottom displacement is smaller, which leads to a 
TABLE 1: Mechanical parameters of various materials.

\begin{tabular}{lcccccc}
\hline Material & $\begin{array}{c}\text { Unit weight } \\
\left(\mathrm{kN} / \mathrm{m}^{3}\right)\end{array}$ & $\begin{array}{c}\text { Height/thickness } \\
(\mathrm{m})\end{array}$ & $\begin{array}{c}\text { Passion's } \\
\text { ratio }\end{array}$ & $\begin{array}{c}\text { Cohesion } \\
(\mathrm{kPa})\end{array}$ & Friction angle $\left(^{\circ}\right)$ & Elastic modules $(\mathrm{MPa})$ \\
\hline Topsoil & 20 & 2.1 & 0.3 & 45 & 14 & 5.94 \\
Intermediary weathered & 23.4 & 37.9 & 0.17 & 300 & 18 & 180 \\
mudstone & 25 & 0.3 & 0.3 & - & - & $3.0 \times 10^{4}$ \\
Segment & 25 & 0.14 & 0.2 & - & - & $1.20 \times 10^{3}$ \\
Grout & 25 & 0.3 & 0.2 & - & - & $3.0 \times 10^{4}$ \\
Pile & & &
\end{tabular}

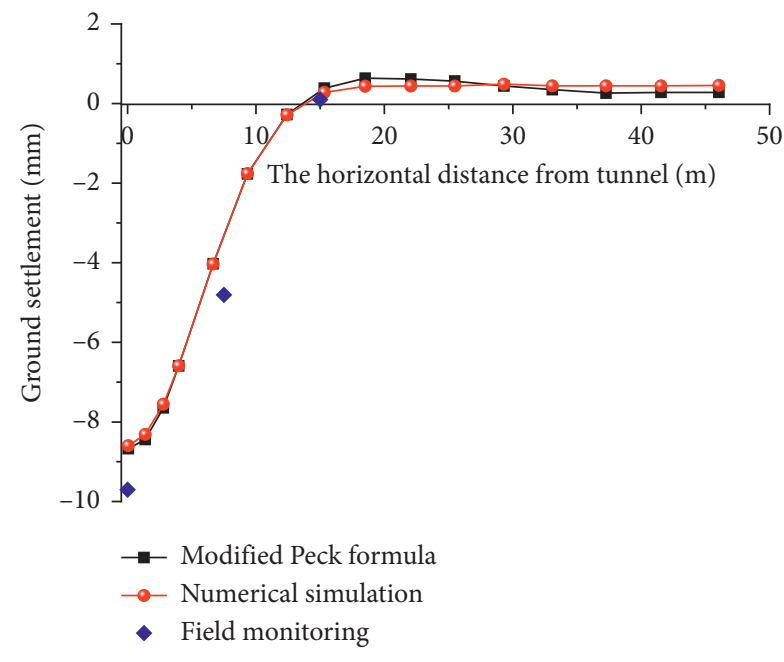

FIGURE 7: The ground settlement trough curve.

larger curvature. The displacement difference maximum is at the bottom, and the deviation rate is $38.71 \%$. This is mainly because of two reasons. On one hand, in order to simplify the calculation, the boundary conditions assume that there are no moment and horizontal constraints at both ends of the pile, but there are a few constraints. On the other hand, the shear stiffness between stratum spring elements is not considered in the single-parameter Winkler model, which will bring some errors to the deformation calculation. Twoparameter Pasternak model with shear stiffness $G_{p}$ between stratum spring elements can be introduced to replace the single-parameter Winkler model adopted in this paper [42-44].

$$
E I \frac{\mathrm{d}^{4} w}{\mathrm{~d} z^{4}}-D G_{p} \frac{\mathrm{d}^{2} w}{\mathrm{~d} z^{2}}+w D k_{h}=u k_{h}
$$

where the meaning of parameters is consistent with Winkle model's. It is worth mentioning that this will also lead to a more complex solution process and parameter validation. A small amount of sacrifice in accuracy is in exchange for the convenience. The latter is of great significance for practical application in engineering. Therefore, the single-parameter Winkler model is chosen in this paper.

Because the horizontal displacement of the stratum is limited by the pile, the stratum will bring reaction force on the pile, resulting in additional internal force. While the horizontal soil bed coefficient $k_{h}^{\prime}$ is $135 \mathrm{MN} / \mathrm{m}^{3}$, the shear force and bending moment of pile are shown in Figures 9 and 10 , respectively. The maximum bending moment occurs

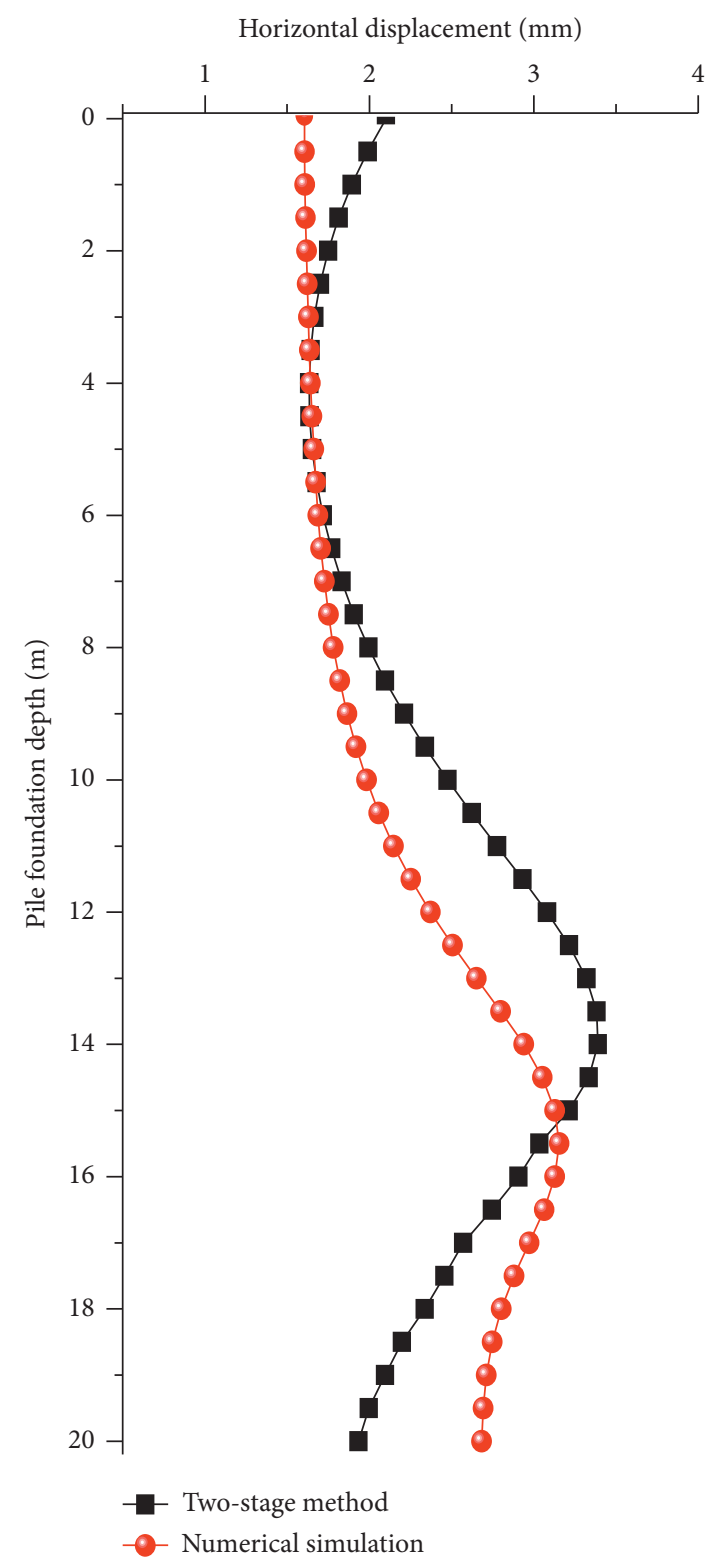

FIgURE 8: Horizontal displacement of pile.

near the burial depth of tunnel, and the tunnel side of pile is in tension, while the shear force reaches the maximum at the top and bottom of tunnel. The results of the two-stage method and numerical simulation are very close. The largest difference is at the peak value, the deviation rate of shear 


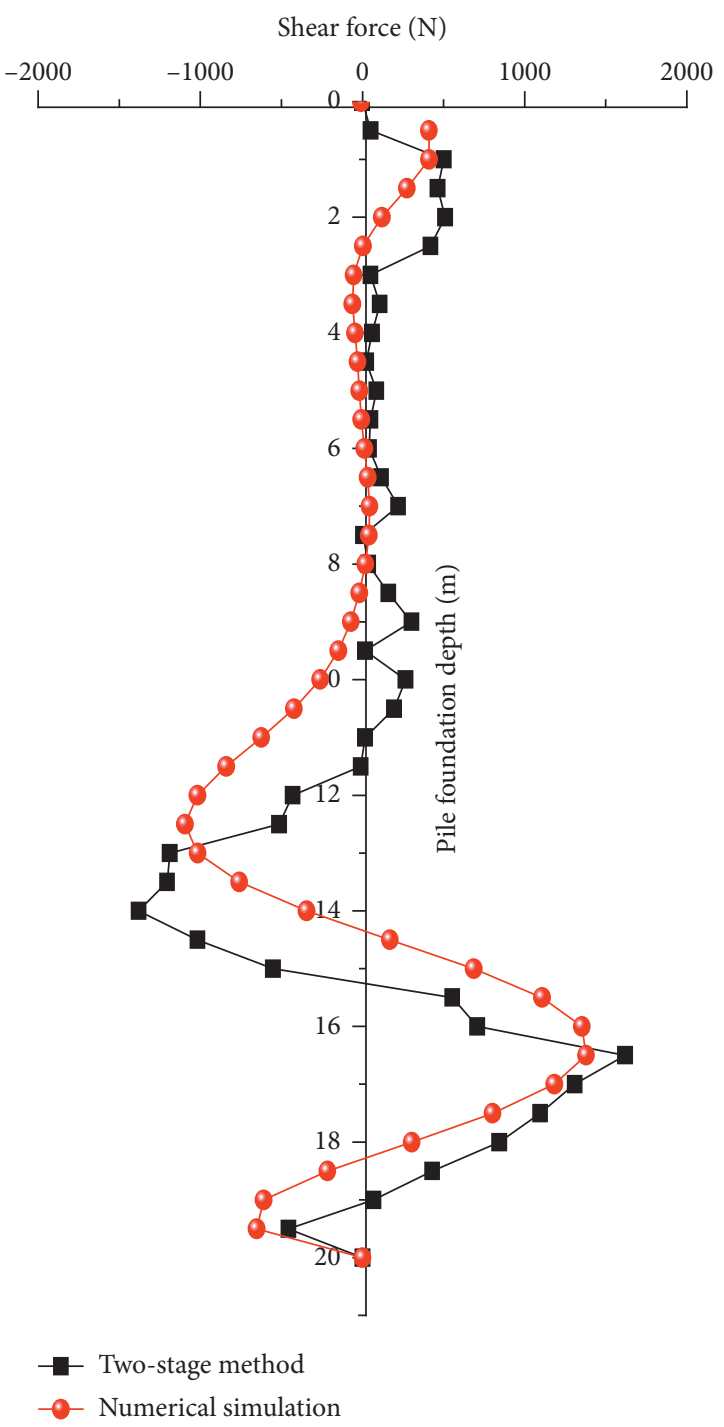

Figure 9: Shear force of pile.

force is $26.14 \%$, and the deviation rate of bending moment is $9.71 \%$. In general, the additional displacement and internal force are at a reasonable and acceptable level.

4.3. Impact Factor Analysis of Pile. The impact degree of shield tunnel construction on adjacent pile foundation is closely related to the horizontal soil bed coefficient $k_{h}^{\prime}$, the pile diameter $D$, and the distance between pile and tunnel $S$. Therefore, the analysis of relevant factors can provide effective guidance for design and construction.

The horizontal displacement difference between pile and tunnel $\Delta s_{x}$ is an important indicator of impact degree. As shown in Figures 11 and 12, $\Delta s_{x}$ increases with the increase of $k_{h}^{\prime}$ and $D$, and the increase rate of $\Delta s_{x}$ is also increasing. When $k_{h}^{\prime}$ increases by $66.7 \%$ from baseline value $75 \mathrm{MN} / \mathrm{m}^{3}$, $\Delta s_{x}$ increases by $40.56 \%$. However, when $D$ increases by $66.7 \%$ from baseline value $0.3 \mathrm{~m}, \Delta s_{x}$ increases by $216.53 \%$. The impact of the pile diameter $D$ on the horizontal displacement difference $\Delta s_{x}$ is much greater than that of the horizontal soil bed coefficient $k_{h}^{\prime}$. This shows that it is more

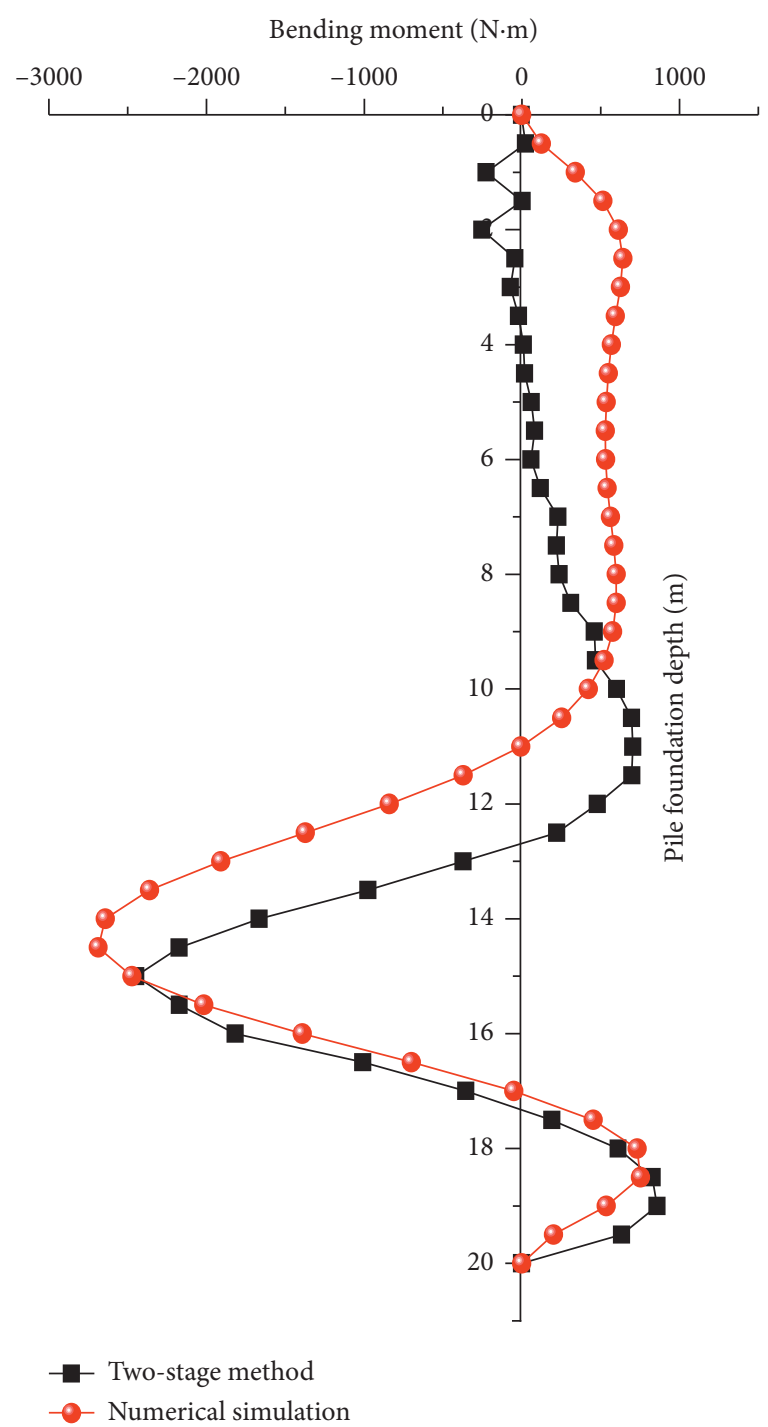

Figure 10: Bending moment of pile.

efficient to optimize the pile diameter than to improve the stratum. The permanent pile foundation should adopt the small diameter pile as far as possible. When the small diameter pile foundation cannot meet the stress requirements, the design scheme of pile group should be adopted. This will reduce the displacement difference between pile and stratum, reduce the additional internal force, and improve the stability of pile foundation.

With the increase of $k_{h}^{\prime}$, the additional internal force of pile foundation increases gradually, but the increase rate decreases slightly, as shown in Figures 13 and 14. This shows that improving stratum is also an effective measure, but considering the high cost, it has a lower priority in practice. As we can see from Figures 15 and 16, the additional internal force of pile foundation is sensitive to the distance between pile and tunnel $S$. The additional moment of pile at $S=0.75 \mathrm{D}$ is about $47 \%$ when $S=0.5 \mathrm{D}$, and that of the additional shear is $42 \%$. While $S$ increases to $1.5 \mathrm{D}$, the additional internal force decreases to about $5 \%$ when $S=0.5$ $D$. When $S \leq 0.75 \mathrm{D}$, the change rate of the additional 


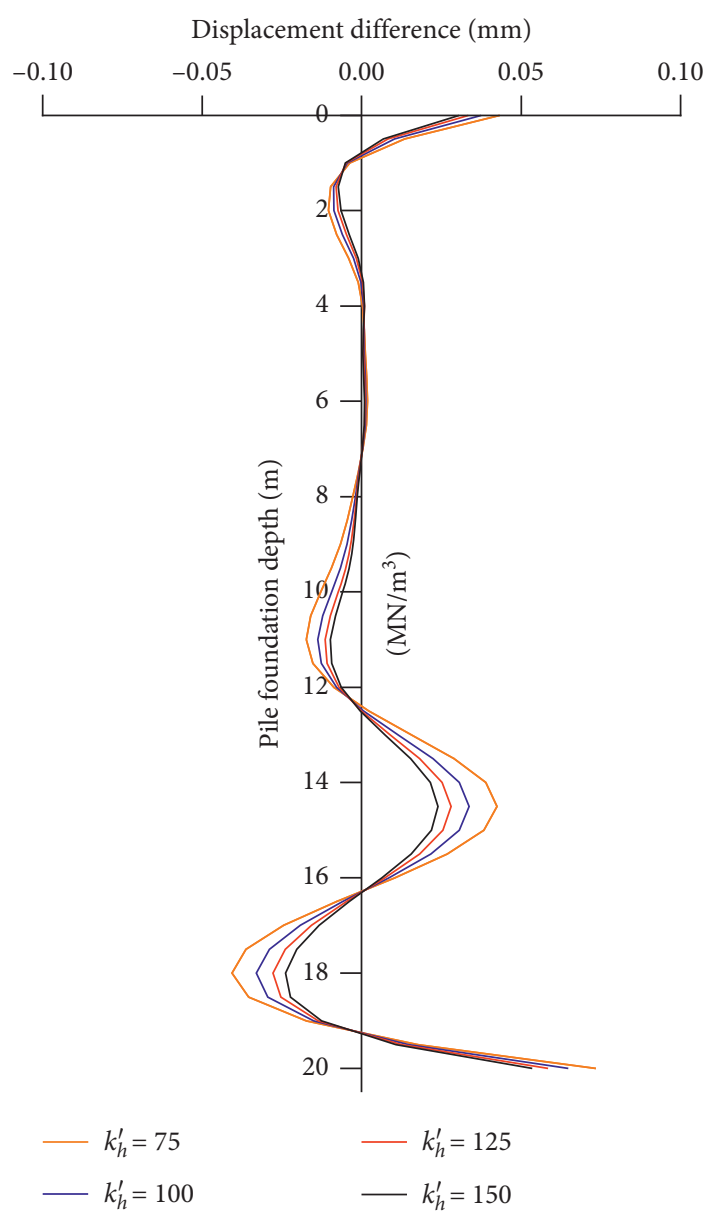

Figure 11: Relation between $k_{h}^{\prime}$ and $\Delta s_{x}$.

internal force is high. The change rate is relatively low at $0.75 \mathrm{D} \leq S \leq 1.5 \mathrm{D}$. While $S>1.5 \mathrm{D}$, the additional internal force stays at a lower level. Based on this rule of pile, the zone around shield tunnel is divided into strong impact zone of pile foundation $(S \leq 0.75 \mathrm{D})$, slight impact zone $(0.75 \mathrm{D} \leq S \leq 1.5 \mathrm{D})$, and no impact zone $(S>1.5 \mathrm{D})$. The pile researched in this paper $(S=0.83 \mathrm{D})$ is in slight impact zone. When designing and constructing shield tunnel, the relative position of pile foundation should be avoided from the strong impact zone and should be in the slight and no impact zone as far as possible. If the pile foundation is unable to be in the strong impact zone, prereinforcement measures should be taken before construction. Stratum movement should be strictly controlled and monitored, reducing the additional internal force of pile foundation.

4.4. Case of Soft-Clay Pile. Due to the pile being surrounded by rock, the pile responses (Deflection, shear force, and bending moment) are not extremely dangerous. Therefore, a case of soft-clay in this section can give readers a more comprehensive understanding about the key mechanistic framework and, besides, expand the applicable range of this method. The physical and mechanical parameters of soft clay are shown in Table 2 [45]. The horizontal displacement,

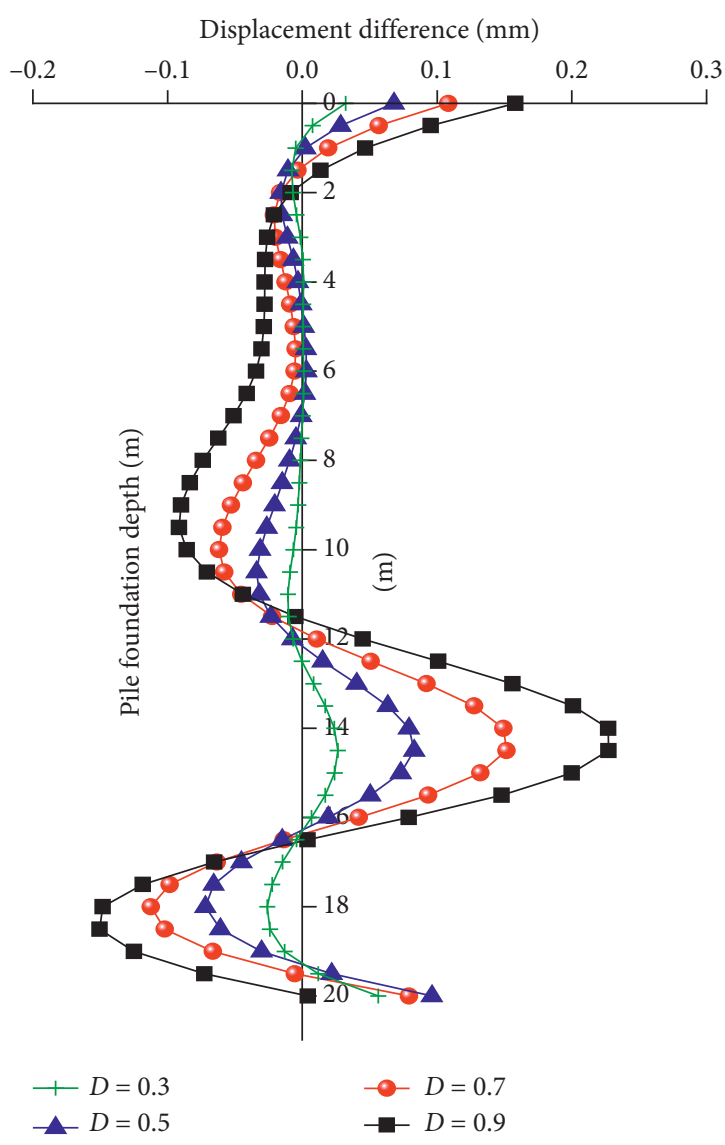

Figure 12: Relation between $D$ and $\Delta s_{x}$.

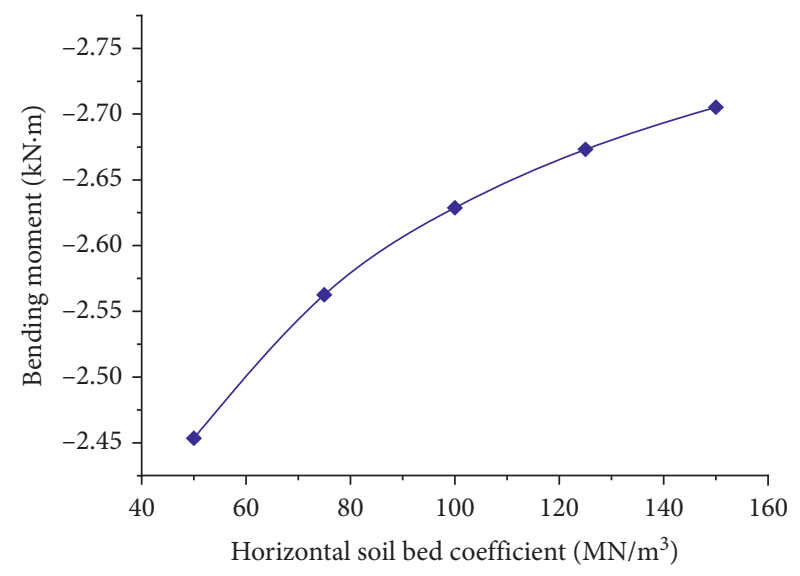

Figure 13: Relation between $k_{h}^{\prime}$ and $M$.

shear force, and bending moment of pile are shown in Figures $17-19$, respectively.

From the figure, in soft soil, good consistency is shown between the two methods, which proves the large applicability of formulas. On the other hand, the maximum of additional displacement is bigger than $2 \mathrm{~cm}$, and its internal forces significantly increase to a dangerous level, $210 \mathrm{kN} \cdot \mathrm{m}$ and $250 \mathrm{kN}$. Generally, the designed bending moment and shear strength of pile like this size are about $200 \mathrm{kN} \cdot \mathrm{m}$ and $200 \mathrm{kN}$, respectively, and the crack resistance strength is only 


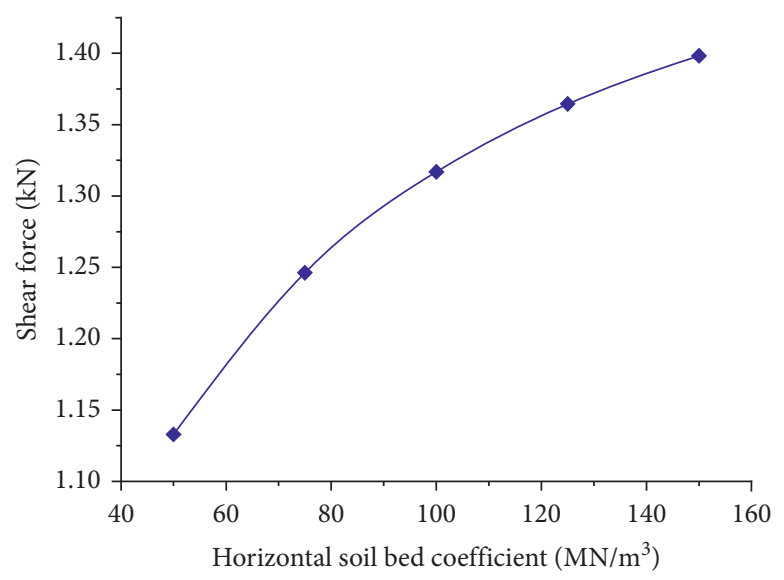

FIGURE 14: Relation between $k_{h}^{\prime}$ and $Q$.

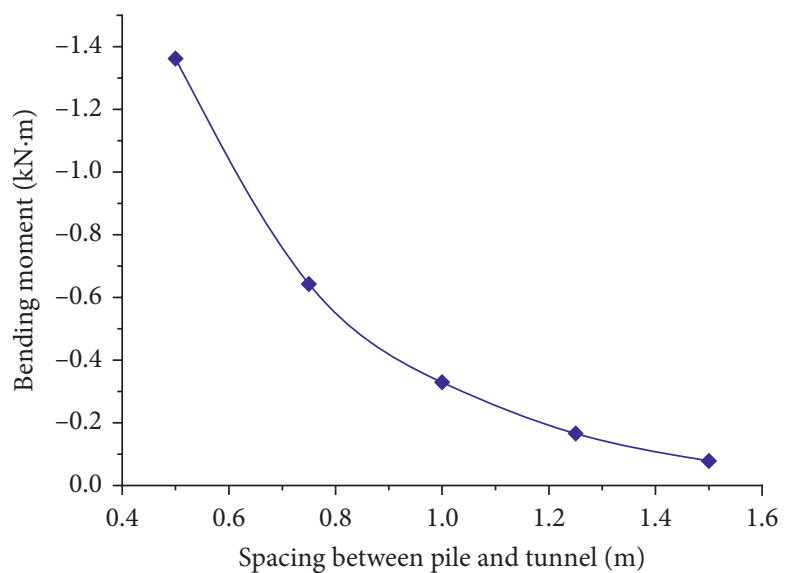

FIgURE 15: Relation between $S$ and $M$.

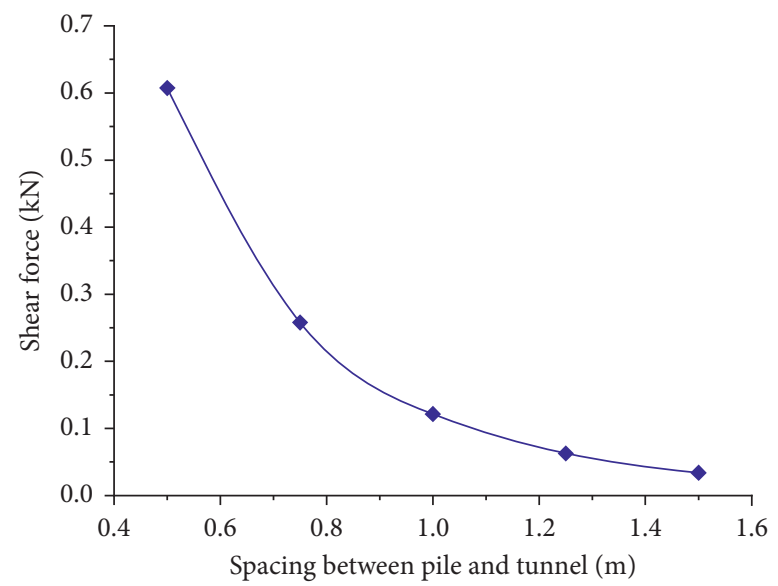

Figure 16: Relation between $S$ and $Q$.

TABLE 2: Mechanical parameters of soft clay [45].

Material Unit weight $\left(\mathrm{kN} / \mathrm{m}^{3}\right)$ Passion's ratio Cohesion $(\mathrm{kPa})$ Friction angle $\left(^{\circ}\right)$ Elastic modules $(\mathrm{MPa}) \quad$ Bed coefficient $\left(\mathrm{kN} / \mathrm{m}^{3}\right)$ Soft clay 18 0.3 20 5 5000 


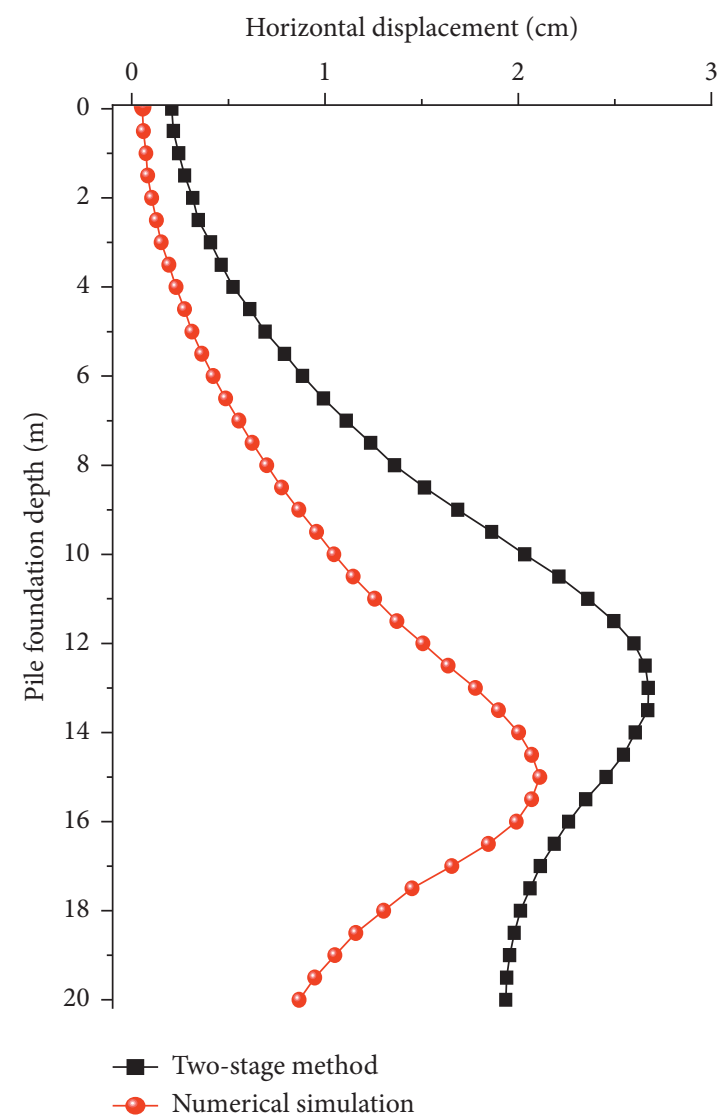

Figure 17: Horizontal displacement of pile in clay.

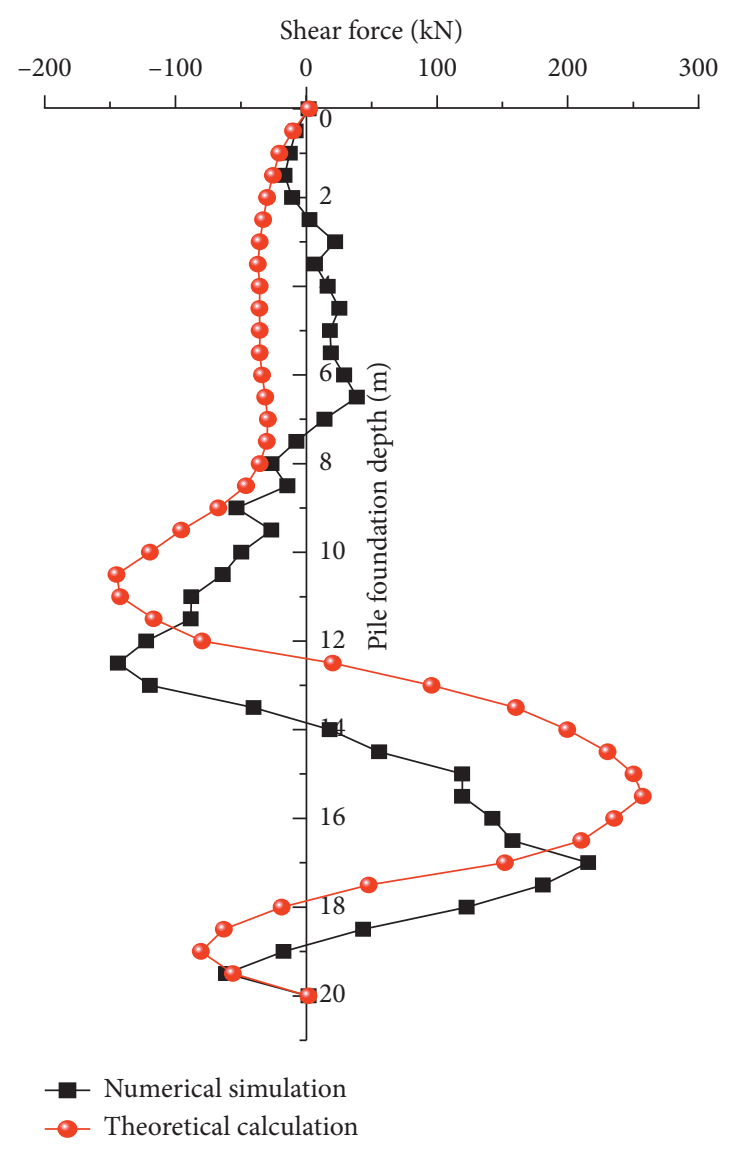

FIGURE 18: Shear force of pile in clay. 


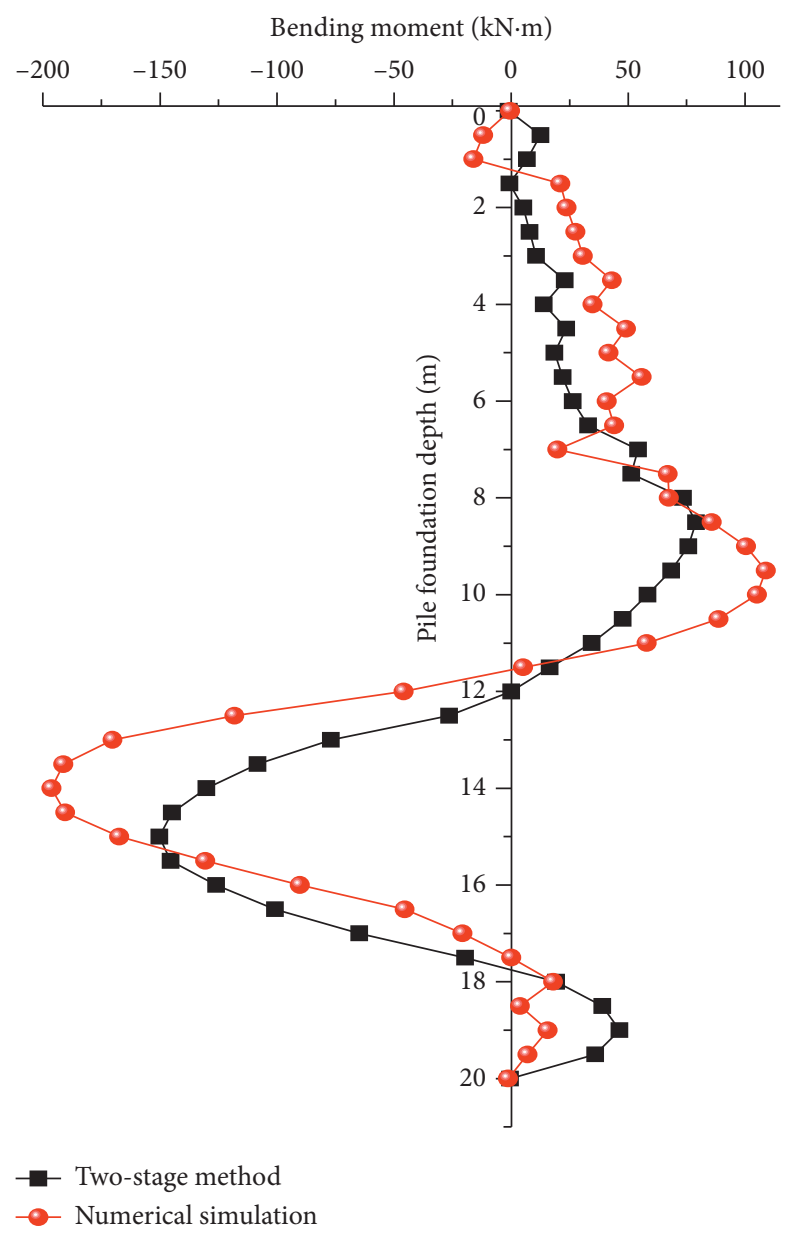

Figure 19: Bending moment of pile in clay.

TABLE 3: Burgers parameters of saturated clay.

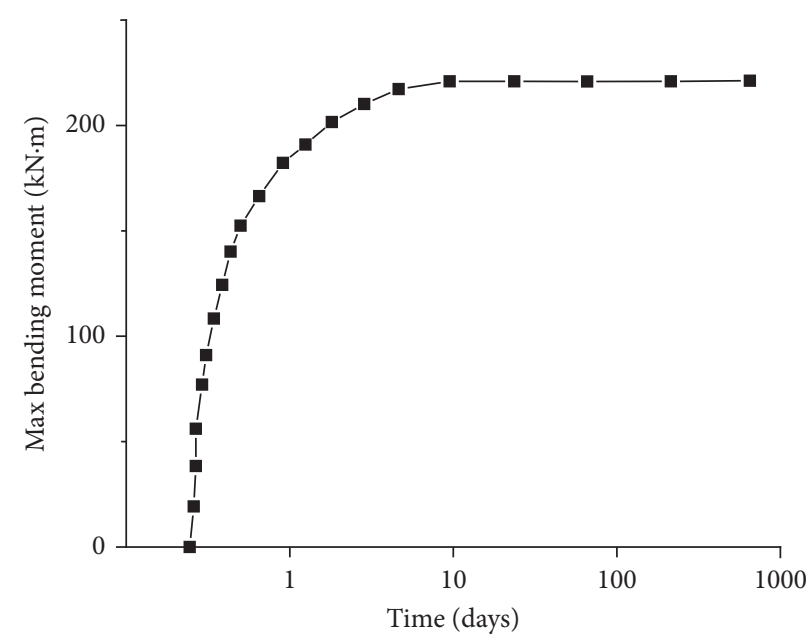

FIgURE 20: The maximum bending moment over time. 
about half of that. This indicates that the pile is insecure under the impact of lateral soil movements, which will make it susceptible to future damages.

And it is noteworthy that excavation in saturated clay will always induce development of excess pore water pressure in the soil, resulting in the time-dependent behavior of pile-soil. The max BM may happen after the excavation and not necessarily during the excavation, which requires longterm analysis and observations always [46-49]. In this paper, Burgers creep model is used to study this process, and the parameters are shown in Table 3.

As shown in Figure 20, the maximum bending moment of pile in saturated clay shows a great time-dependent behavior, and the BM value increases significantly first, then gradually slows down, and finally stabilizes at $220 \mathrm{kN} \cdot \mathrm{m}$; it takes about 10 days. This is because the disturbance of shield excavation leads to the redistribution of pore water pressure in the surrounding soil, resulting in soil reconsolidation.

\section{Conclusions}

This paper presents a new method for impact analysis of shield excavation on an adjacent pile foundation. A modified Peck formula and a three-dimensional numerical model are firstly validated with the field monitoring data in ground settlement. Then, based on the validated parameters, the additional displacement and internal force of the pile foundation are evaluated through a two-stage method and numerical model. Finally, the impact degree of the horizontal soil bed coefficient, the pile diameter, and the distance between pile and tunnel are discussed. The following conclusions are drawn:

(1) Not only the vertical settlement of soil caused by shield construction, but the horizontal displacement can also be calculated by Modified Peck formula. It can be used for many purposes, and the empirical parameters of formula are also convenient to use field monitoring data to back-analysis modification. In this paper, the good consistency between numerical simulation and theoretical calculation and monitoring data of ground settlement verifies the rationality of parameter selection.

(2) In general, the additional displacement and internal force are at a reasonable and acceptable level. The results of the two-stage method and numerical simulation presented are generally close, but there are relatively large differences at bottom of the pile and at the peak displacement. This is because the shear stiffness between stratum spring elements is not considered in the single-parameter Winkler model, which will bring some errors to the deformation calculation. Two-parameter Pasternak model can be introduced to replace the single-parameter Winkler model adopted in this paper. It is worth mentioning that this will also lead to a more complex solution process and parameter validation. Therefore, the single-parameter Winkler model is chosen in this paper.
(3) The impact of the pile diameter $D$ on the horizontal displacement difference $\Delta s_{x}$ is much greater than that of the horizontal soil bed coefficient $k_{h}^{\prime}$. This shows that it is more efficient to optimize the pile diameter than to improve the stratum. The permanent pile foundation should adopt the small diameter pile as far as possible. When the small diameter pile foundation cannot meet the stress requirements, the design scheme of pile group should be adopted.

(4) The additional internal force of pile foundation is sensitive to the distance between pile and tunnel $S$. Based on the change rule of pile internal force, the zone around shield tunnel is divided into strong impact zone of pile foundation $(S \leq 0.75 \mathrm{D})$, slight impact zone $(0.75 \mathrm{D} \leq S \leq 1.5 \mathrm{D})$, and no impact zone $(S>1.5 \mathrm{D})$. The pile researched in this paper $(S=0.83 \mathrm{D})$ is in the slight impact zone. When designing and constructing shield tunnel, the relative position of pile foundation should be avoided from the strong impact zone and should be in the slight and no impact zone as far as possible.

(5) In order to give a more comprehensive mechanistic framework and the applicable range of this method, a case in soft-clay is applied. The results show that the maximum of additional displacement is bigger than $2 \mathrm{~cm}$, and internal forces significantly increase and even exceed the design strength. This indicates that the pile is insecure under the impact of lateral soil movements, which will make it susceptible to future damages. In saturated clay, this process shows obvious time-dependent behavior, and the maximum bending moment happens after the excavation rather than during the excavation. The final value is slightly larger than that of the elastoplastic method.

\section{Data Availability}

The data used to support the findings of this study are available from the corresponding author upon request.

\section{Conflicts of Interest}

The authors declare no conflicts of interest.

\section{Acknowledgments}

The authors highly appreciate the contribution of data collection from China Railway No. 9 Group Co., Ltd. This study was supported by the High Speed Railway and Natural Science United Foundation of China (U1934213), the Project of Nanchang Metro-Study on Key Technology of Subway Tunnel under Existing Line in Water Rich Composite Stratum (HG-2020-4A-CP-A-ZX-003), and the National Natural Science Foundation of China (NSFC) under Grant no. 51508037. 


\section{References}

[1] H. Sun, L. Wang, S. Chen, H. Deng, and J. Zhang, "A precise prediction of tunnel deformation caused by circular foundation pit excavation," Applied Sciences, vol. 9, no. 11, p. 2275, 2019.

[2] J.-f. Zou, Z.-h. Qian, X.-h. Xiang, and G. h. Chen, "Face stability of a tunnel excavated in saturated nonhomogeneous soils," Tunnelling and Underground Space Technology, vol. 83, pp. 1-17, 2019.

[3] J. C. Sun, H. Zhang, P. Tu et al., "Research on construction mechanical behaviour of connecting aisle in shield tunnel," IOP Conference Series: Earth and Environmental Science, vol. 167, Article ID 012041, 2018.

[4] F. Lin, S. G. Chen, and H. Zhang, Study on Type Selection of Shield Equipment in Different Geological Conditions, Green Building, Materials and Civil Engineering, CRC Press, Boca Raton, FL, USA, 2014.

[5] Z. L. Zhou, S. G. Chen, and Y. S. Li, "Research on predicting and distribution of stratum displacement of double-tube parallel shield tunnel," Journal of Highway and Transportation Research and Development, vol. 32, pp. 109-117, 2015.

[6] H. Zhang, S. G. Chen, and X. F. Deng, "Analysis of the influence of shield driving parameters on ground settlements," Modern Tunnelling Technology, vol. 47, pp. 48-53, 2010.

[7] H. Zhang, S. G. Chen, and X. R. Tan, "Research on the mechanical behavior of a segment of a shield tunnel adjacent to a pile foundation," Modern Tunnelling Technology, vol. 49, pp. 101-107, 2012.

[8] H. Zhang, S. G. Chen, and X. F. Deng, "Analysis on influence of shield tunneling on ground and bridge pile," Chinese Journal of Underground Space and Engineering, vol. 7, pp. 552-557, 2011.

[9] X. Xie, Y. Yang, and M. Ji, "Analysis of ground surface settlement induced by the construction of a large-diameter shield-driven tunnel in Shanghai, China," Tunnelling and Underground Space Technology, vol. 51, pp. 120-132, 2016.

[10] X. J. Wei, J. Hong, and G. Wei, "Analysis of additional load on adjacent pile foundation induced by double-o-tube shield tunnel construction," Rock and Soil Mechanics, vol. 34, pp. 783-790, 2013.

[11] Q. Xu, H. Zhu, X. Ma et al., "A case history of shield tunnel crossing through group pile foundation of a road bridge with pile underpinning technologies in Shanghai," Tunnelling and Underground Space Technology, vol. 45, pp. 20-33, 2015.

[12] C. Li, Z. Zhong, G. He, and X. Liu, "Response of the ground and adjacent end-bearing piles due to side-by-side twin tunnelling in compound rock strata," Tunnelling and Underground Space Technology, vol. 89, pp. 91-108, 2019.

[13] M. Nematollahi and D. Dias, "Three-dimensional numerical simulation of pile-twin tunnels interaction-case of the Shiraz subway line," Tunnelling and Underground Space Technology, vol. 86, pp. 75-88, 2019.

[14] G. Meschke, J. Ninić, J. Stascheit, and A. Alsahly, "Parallelized computational modeling of pile-soil interactions in mechanized tunneling," Engineering Structures, vol. 47, pp. 35-44, 2013.

[15] C. Liu, Z. Zhang, and R. A. Regueiro, "Pile and pile group response to tunnelling using a large diameter slurry shield-case study in Shanghai," Computers and Geotechnics, vol. 59, pp. 21-43, 2014.

[16] H. Mroueh and I. Shahrour, "Three-dimensional finite element analysis of the interaction between tunneling and pile foundations," International Journal for Numerical and
Analytical Methods in Geomechanics, vol. 26, no. 3, pp. 217230, 2002.

[17] Z. Zhang and M. Zhang, "Mechanical effects of tunneling on adjacent pipelines based on galerkin solution and layered transfer matrix solution," Soils and Foundations, vol. 53, no. 4, pp. 557-568, 2013.

[18] N. T. V. Phuong, A. F. Van Tol, A. S. K. Elkadi, and A. Rohe, "Numerical investigation of pile installation effects in sand using material point method," Computers and Geotechnics, vol. 73, pp. 58-71, 2016.

[19] F. Dezi, S. Carbonari, and M. Morici, "A numerical model for the dynamic analysis of inclined pile groups," Earthquake Engineering \& Structural Dynamics, vol. 45, no. 1, pp. 45-68, 2016.

[20] H. G. Poulos, "Comparisons between measured and computed responses of piles adjacent to tunnelling operations," Géotechnique Letters, vol. 1, no. 2, pp. 11-15, 2011.

[21] R. B. J. Brinkgreve and W. Broere, "The influence of tunnel boring on foundations and buildings in urban areas-a numerical study," in Proceedings of the 2003 International Workshop on Geotechnics of Soft Soils, Noordwijkerhoud, Netherlands, 2003.

[22] K. J. Xu and H. G. Poulos, "3-D elastic analysis of vertical piles subjected to "passive" loadings," Computers and Geotechnics, vol. 28, no. 5, pp. 349-375, 2001.

[23] N. Loganathan, H. G. Poulos, and K. J. Xu, "Ground and pilegroup responses due to tunnelling," Soils and Foundations, vol. 41, no. 1, pp. 57-67, 2001.

[24] P. Kitiyodom, T. Matsumoto, and K. Kawaguchi, "A simplified analysis method for piled raft foundations subjected to ground movements induced by tunnelling," International Journal for Numerical and Analytical Methods in Geomechanics, vol. 29, no. 15, pp. 1485-1507, 2005.

[25] A. M. Marshal and T. Haji, "An analytical study of tunnel-pile interaction," Tunnelling and Underground Space Technology, vol. 45, pp. 43-51, 2015.

[26] F. Basile, "Effects of tunnelling on pile foundations," Soils and Foundations, vol. 54, no. 3, pp. 280-295, 2014.

[27] Z. Zhang, M. Huang, C. Xu, Y. Jiang, and W. Wang, "Simplified solution for tunnel-soil-pile interaction in Pasternak's foundation model," Tunnelling and Underground Space Technology, vol. 78, pp. 146-158, 2018.

[28] H.-N. Wu, S.-L. Shen, J. Yang, and A. Zhou, "Soil-tunnel interaction modelling for shield tunnels considering shearing dislocation in longitudinal joints," Tunnelling and Underground Space Technology, vol. 78, pp. 168-177, 2018.

[29] A. Franza, A. M. Marshall, T. Haji, A. O. Abdelatif, S. Carbonari, and M. Morici, "A simplified elastic analysis of tunnel-piled structure interaction," Tunnelling and Underground Space Technology, vol. 61, pp. 104-121, 2017.

[30] R. B. Peck, "Deep excavations and tunnelling in soft ground," in Proceedings of the 7th International Conference on Soil Mechanics and Foundation Engineering, Mexico City, MO, USA, 1969.

[31] S. Knothe, "Observations of surface movements under influence of mining and their theoretical interpretation," in Proceedings of 1957 European Conference on Ground Movement, Leeds, UK, 1957.

[32] P. C. Lim and O. Sigl, "An estimate of subsurface settlement trough width parameter for G4 material," Tunnels and Underground Structures, pp. 507-513, A. A. Balkema, Rotterdam, Netherlands, 2000. 
[33] J. H. Atkinson and D. M. Potts, "Subsidence above shallow tunnels in soft ground," Journal of the Geotechnical Engineering Division, vol. 103, no. 4, pp. 307-325, 1977.

[34] X. Han, The Analysis and Prediction of Tunnelling-Induced Building Deformations, Xi'an University of Technology, Xi'an, China, 2006.

[35] R. J. Mair, R. N. Taylor, and A. Bracegirdle, "Subsurface settlement profiles above tunnels in clays," Géotechnique, vol. 43, no. 2, pp. 315-320, 1993.

[36] Y. Y. Xia, C. S. Chen, M. Bakri et al., "Analysis of horizontal displacement of soil induced by shallow tunnel excavation," Rock and Soil Mechanics, vol. 36, pp. 354-360, 2015.

[37] P. B. Attewell, J. Yeates, and A. R. Selby, Soil Movements Induced by Tunnelling and Their Effects on Pipelines and Structures, Blackie, Glasgow, Scotland, 1986.

[38] Z. Li and M. Huang, "Analysis of settlement and internal forces of group pile due to tunneling," Chinese Journal of Geotechnical Engineering, vol. 29, pp. 398-402, 2007.

[39] C. Zhang, P. Deng, and W. Ke, "Assessing physical mechanisms related to kinematic soil-pile interaction," Soil $D y$ namics and Earthquake Engineering, vol. 114, pp. 22-26, 2018.

[40] R. Zhang, J. Zheng, H. Pu, and L. Zhang, "Analysis of excavation-induced responses of loaded pile foundations considering unloading effect," Tunnelling and Underground Space Technology, vol. 26, no. 2, pp. 320-335, 2011.

[41] Ministry of Construction of PRC, Standard for Soil Test Method (GB/T 50123-1999), China Planning Press, Beijing, China, 1999.

[42] C. P. Filipich and M. B. Rosales, "A further study about the behaviour of foundation piles and beams in a Winkler-Pasternak soil," International Journal of Mechanical Sciences, vol. 44, no. 1, pp. 21-36, 2002.

[43] J. Wang, D. Zhou, and W. Liu, "Horizontal impedance of pile groups considering shear behavior of multilayered soils," Soils and Foundations, vol. 54, no. 5, pp. 927-937, 2014.

[44] Z. Zhang, M. Huang, C. Zhang, K. Jiang, and M. Lu, “Timedomain analyses for pile deformation induced by adjacent excavation considering influences of viscoelastic mechanism," Tunnelling and Underground Space Technology, vol. 85, pp. 392-405, 2019.

[45] J. H. Lee, Y. Kim, and S. Jeong, "Three-dimensional analysis of bearing behavior of piled raft on soft clay," Computers and Geotechnics, vol. 37, no. 1-2, pp. 103-114, 2010.

[46] D. E. L. Ong, C. F. Leung, and Y. K. Chow, "Time-dependent pile behaviour due to excavation-induced soil movement in clay," in Proceedings of the 12th Pan-American Conference on Soil Mechanics and Geotechnical Engineering, Cambridge, MA, USA, 2003.

[47] D. E. L. Ong, C. F. Leung, and Y. K. Chow, "Piles subject to excavation-induced soil movement in clay," in Proceedings of the 13th European Conference on Soil Mechanics and Geotechnical Engineering, Prague, Czech Republic, 2003.

[48] D. E. L. Ong and C. S. Choo, "Sustainable bored pile construction in erratic phyllite," in Proceedings of the 2011 ASEAN-Australian Engineering Congress, Kuching, Malaysia, July 2011.

[49] D. E. L. Ong, D. Q. Yang, and S. K. Phang, "Comparison of finite element modelling of a deep excavation using SAGECRISP and PLAXIS," in Proceedings of the International Conference on Deep Excavations, Singapore, 2006. 